NBER WORKING PAPER SERIES

\title{
THE RECENT RISE OF LABOR FORCE PARTICIPATION OF OLDER WORKERS IN SWEDEN
}

\author{
Lisa Laun \\ Mårten Palme \\ Working Paper 24593 \\ http://www.nber.org/papers/w24593 \\ NATIONAL BUREAU OF ECONOMIC RESEARCH \\ 1050 Massachusetts Avenue \\ Cambridge, MA 02138 \\ May 2018
}

This paper is part of the National Bureau of Economic Research's International Social Security (ISS) Project, which is supported by the National Institute on Aging (grant P01 AG012810). Lisa Laun gratefully acknowledges financial support from the Swedish Research Council for Health, Working Life and Welfare, FORTE (dnr 2013-0209). The views expressed herein are those of the authors and do not necessarily reflect the views of the National Bureau of Economic Research.

NBER working papers are circulated for discussion and comment purposes. They have not been peer-reviewed or been subject to the review by the NBER Board of Directors that accompanies official NBER publications.

(C) 2018 by Lisa Laun and Mårten Palme. All rights reserved. Short sections of text, not to exceed two paragraphs, may be quoted without explicit permission provided that full credit, including (C) notice, is given to the source. 
The Recent Rise of Labor Force Participation of Older Workers in Sweden

Lisa Laun and Mårten Palme

NBER Working Paper No. 24593

May 2018

JEL No. J26

\title{
$\underline{\text { ABSTRACT }}$
}

This paper studies the background to the increase in labor force participation of older workers in Sweden since 2000. In the first part, we study how the characteristics of the elderly have changed with respect to health, education level and work environment, as well as the impact of joint decision-making within the household. In the second part, we study the importance of institutional changes, including a major reform of the old-age pension system, introduction of tax credits for older workers, changes of the mandatory retirement age and stricter eligibility criteria in the disability insurance program. We find that the rise in labor force participation has coincided with improvements in health and educational attainment across birth cohorts as well as increased screening stringency in the disability insurance program.

\author{
Lisa Laun \\ Institute for Evaluation of Labour Market \\ and Education Policy (IFAU) \\ Box 513 \\ SE-751 20 Uppsala \\ Sweden \\ Lisa.Laun@ifau.uu.se \\ Mårten Palme \\ Department of Economics \\ Stockholm University \\ SE-106 91 Stockholm \\ SWEDEN \\ and IZA \\ Marten.Palme@ne.su.se
}




\section{$1 \quad$ Introduction}

Between 1963 and 2000 the labor force participation rate among males in the age group 60-64 in Sweden fell from around 85 to 55 percentage points (see, e.g., Palme and Svensson, 1999). However, since then, the labor force participation has started to rise again and is now above 75 percent in the age group (see, e.g., Johansson et al., 2015). Although the long term development for female labor force participation has been dominated by the great increase in employment of married women, the recent development shows a similar pattern to that of the males.

In this paper we analyze the background to the recent increase in labor force participation of older workers in Sweden. We first look at how the population has changed with respect to characteristics known to be associated with the probability to be active at the labor market among older people. These characteristics are health, educational attainment and the work environment that the worker will meet if he or she decides to work. Finally, considering the pattern of joint retirement decision of couples, we look at to what extent the increased labor force participation rate of married women could explain the increased probability of working among older men.

In the second part of the paper, we study to what extent the recent institutional changes of the income security system and labor market regulations may have contributed to the development. First, we look briefly at the potential effects of the great reform of the old-age pension system in Sweden that was initiated in 1998. Second, we study the effects of the introduction of age-targeted income tax credits in 2007. Third, we summarize the experiences of the change in the mandatory retirement age in 2001. Finally, we study the potential effects of the more stringent rules for eligibility in Sweden's disability insurance program that were gradually implemented.

We do not attempt to identify any "causal effects" of any policy intervention. Our analysis is merely descriptive in the sense that we look at coincidences of trends or long-term changes in the society. Throughout we have chosen to look at males and females separately. The reason for this choice, as will be apparent from our description in Section 2, is that men and women experienced a very different development in their participation in the labor force in the most recent decades. 


\section{The Development of Labor Force Participation and Employment of Older Workers in Sweden}

Figure 1 shows the evolution of labor force participation for 55-59, 60-64 as well as 65-69 year olds for males and females, respectively. By comparing the graphs for males aged 60-64 with the corresponding one for those aged 55-59, it can be seen that the development follows the same pattern, although the development for the older age group is more dramatic: there is a marked trend towards decreased labor force participation until the late 1990s in both age groups and then a reversed trend. In the 60-64 age group there is a decrease from 85 percent in 1963 to about 57 percent in the year 2000 and then an increase to around 75 percent by the end of the period. The corresponding change in the 55-59 age group is from almost 95 percent to below 85 percent in the year 2000 and then a recovery to about 90 percent.

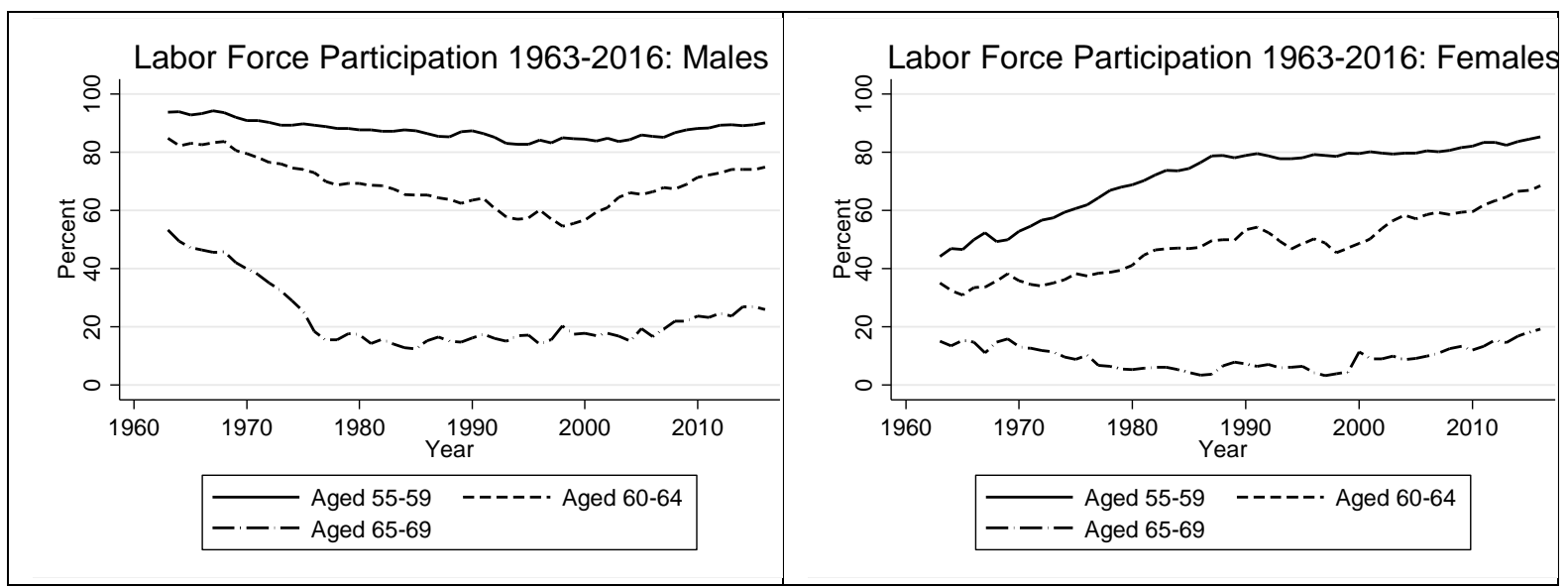

Figure 1. The development of labor force participation rates in different age groups 19632016. Males and Females. Source: Swedish Labour Force Survey.

For the oldest age group, those aged 65-69, the graph shows a marked decrease in labor force participation until the late 1970s. This primarily reflects the gradual change in the mandatory and normal retirement ages from 67 to 65 on the Swedish labor market. The graph also shows a marked increase in labor force participation by the end of the period under study: from below 20 percent in the year 2000 to around 26 percent by the end of the period.

As is immediately apparent from the figures, the graphs for female labor force participation tell a very different story from the male ones. The development for females until the late 1980s is dominated by the trend towards increased labor force participation. After that, the development for the two gender groups has been remarkably parallel. 
This development is highlighted in Figure 2. In this figure, the graphs for the two gender groups in the same age group have been placed in the same diagram. It can be seen that the convergence between males and females happened five years later in the age group 60-64 compared to the 55-59 one, which is a pure cohort effect. This means that the increase in female labor force participation relative to the male labor force participation stopped around the cohort born in 1935. There is no tendency to further convergence in labor force participation for cohorts born later.

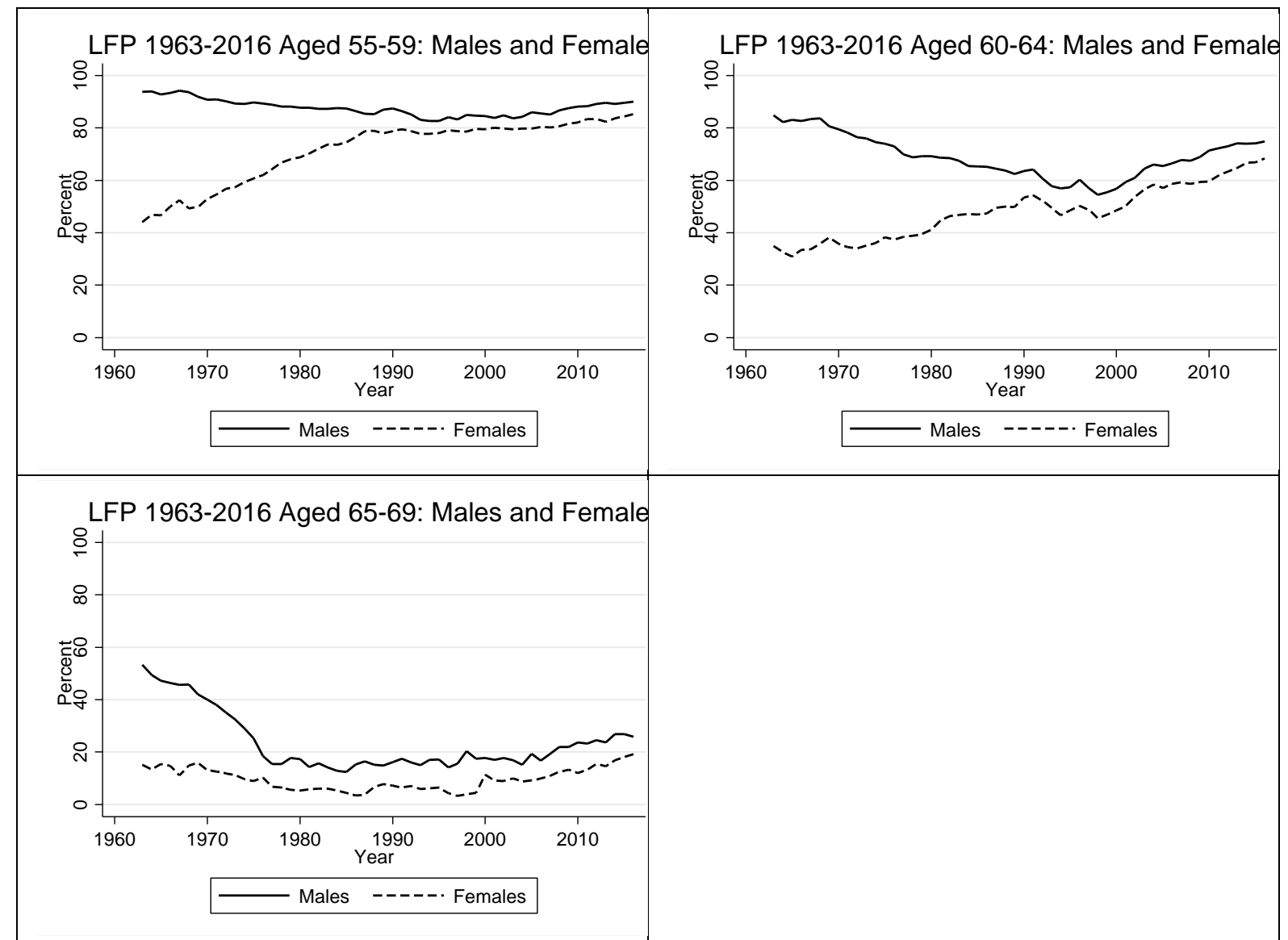

Figure 2. The development of labor force participation rates for males compared to females in different age groups 1963-2016. Source: Swedish Labour Force Survey.

Figure 3 shows the development of the employment rate for the same age groups as in Figure 1 over the same period. It can be seen that this development follows a very similar pattern compared to the labor force participation rates. This means that the unemployment rate is not driving the long-term changes in employment. Figure 4 shows the development of 
unemployment rates separately. It can be seen that this development is closely connected to the Swedish business cycle, with major recessions in the early 1980 and 1990s.

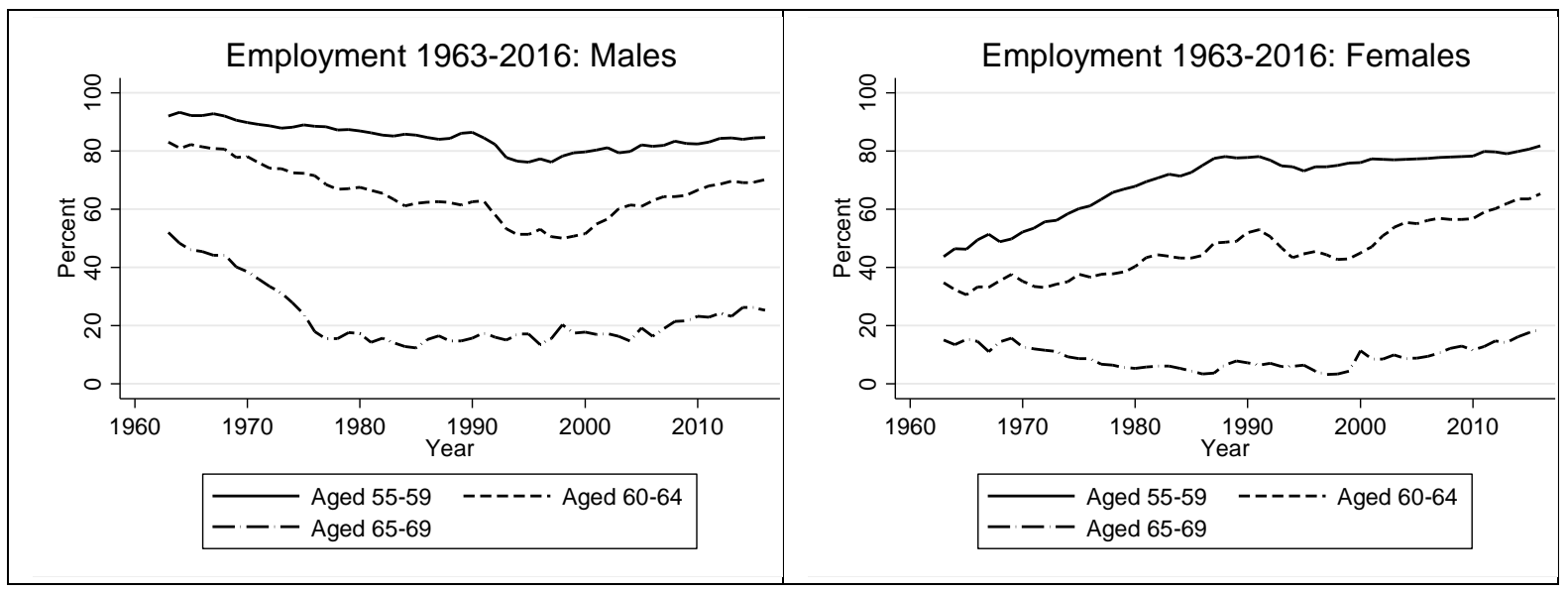

Figure 3. The development of employment by age 1963-2016. Males and Females. Source: Swedish Labour Force Survey.

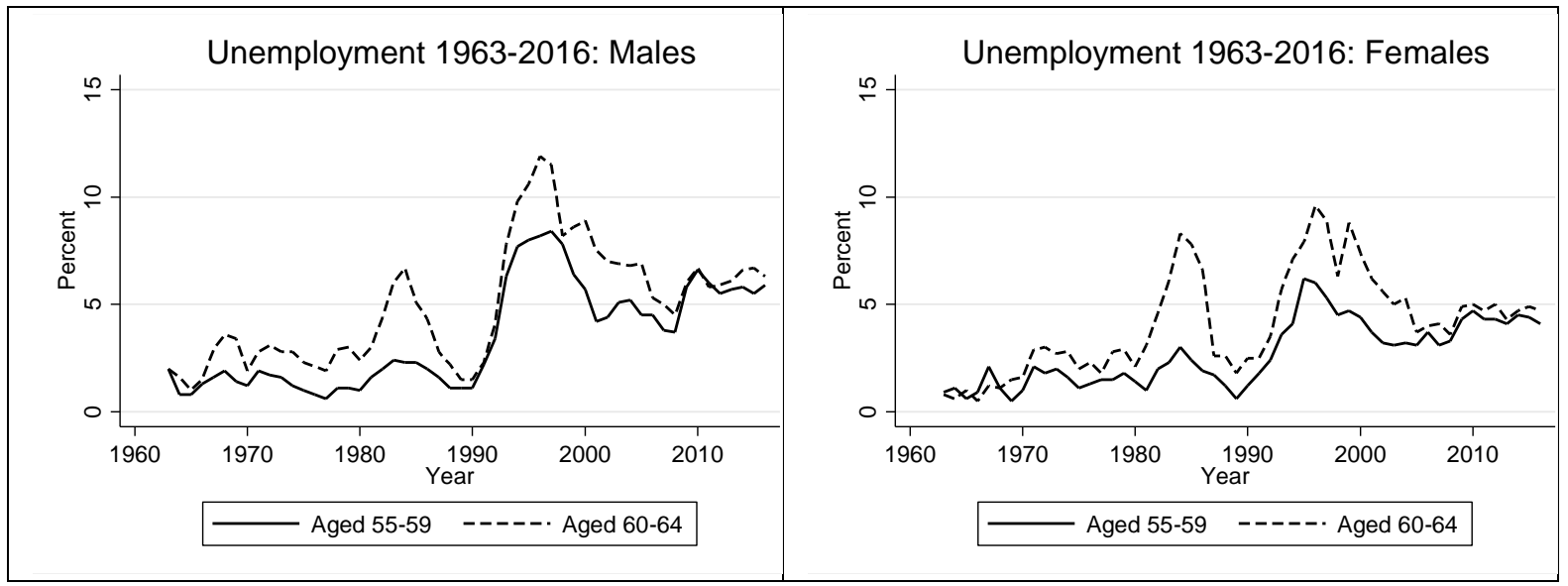

Figure 4. The development of employment by age 1963-2016. Males and Females. Source: Swedish Labour Force Survey.

To sum up, there is a U-shaped development of labor force participation of older men in Sweden over the observed period. Although it has been a strong trend towards a higher labor force participation in recent years, it should be noted that the average rates are still much below the ones observed in the early 1960s in all age groups under study. The diagrams where we placed the graphs for the development of male and female labor force participation in the same age groups together suggest that there is no increase in the relative female labor force participation after the cohort born in 1935. These graphs also suggest that the recent trend toward increased male labor force participation is driven by changes across birth cohorts rather than by period effects. This interpretation is further supported by the fact that business cycle 
changes and fluctuations in the unemployment rate seem to have very limited effects on the labor force participation rates.

\section{Changes in Characteristics of the Population aged 55-59 and 60-64}

\subsection{Improved Health}

A possible background to the higher labor force participation rates is that the population simply improved their health status, allowing them to work in older ages. A first problem when assessing the empirical relevance of the hypothesis is how to measure changes in population health. One way is to look at changes in mortality. Figure 5 shows the development of mortality rates between 1960 and 2015 in the age groups 55-59 and 60-64 and for males and females, respectively.

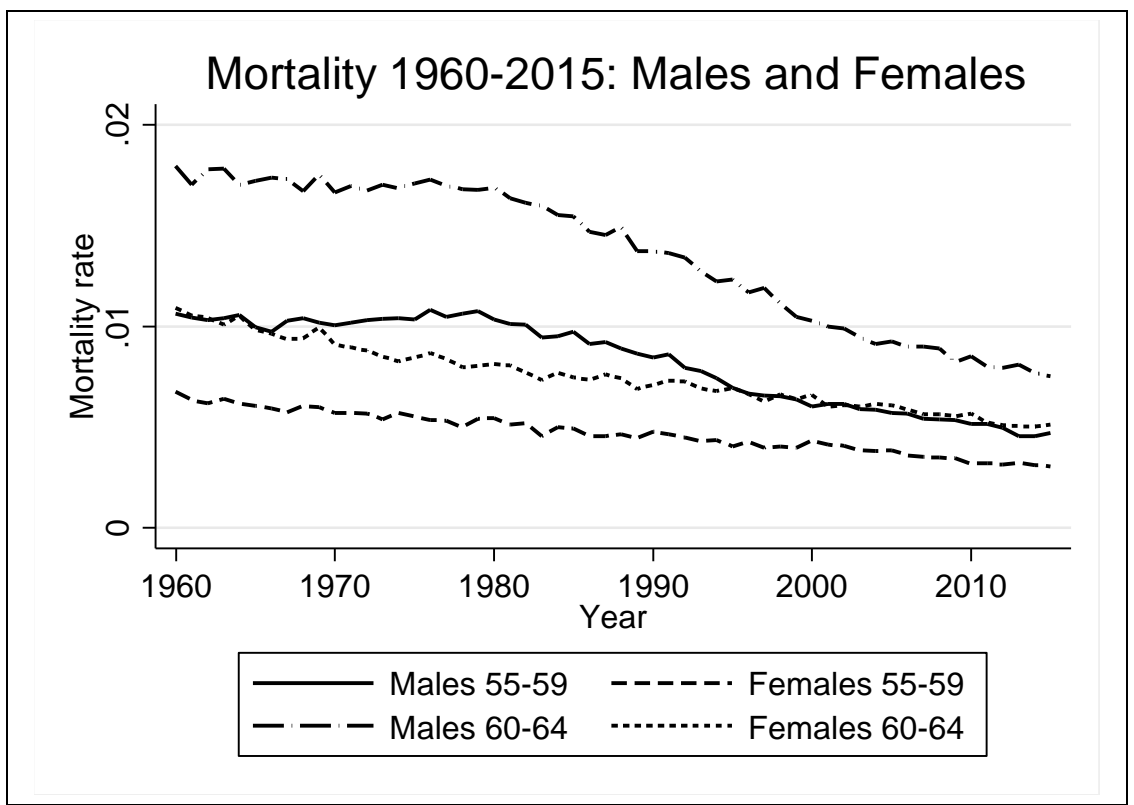

Figure 5. Development of mortality rates 1960-2015. Age groups 55-59 and 60-64. Males and Females. Source: The Swedish Cause of Death Register.

Figure 5 shows several interesting patterns in the development of mortality. While there is a steady improvement in survival for women in both age groups, the development shows little change for men between 1960 and the mid-1980s. However, since then, there is a larger decrease in mortality for men than for women. The gender gap in mortality in the older age 
group has shrunk markedly in recent years. In the 25-year period since 1980, the mortality rate among men aged 60-64 has more than halved from about $1.7 \%$ to below $0.8 \%$.

A limitation of using mortality to analyze the background to changes in labor force participation is its low validity: the marginal worker is probably different from the marginal survivor in the ages under study. It is conceivable that much of the improvement in survival rates in recent years is located in groups of people that are far from entering the labor force.

A complement to the mortality rates is to look at the development of self-assessed health measures. We use data on self-assessed health obtained from the six different waves of the Swedish Level of Living Survey (LNU). The LNU is a panel survey administrated by the Institute for Social Research at Stockholm University, where about 6,000 individuals aged 1674 are interviewed about their health, work, social contacts, economic conditions as well as their participation in the society. ${ }^{1}$

Figure 6 shows the development of three different health indicators obtained from survey questions. The first one asks about the ability to walk in stairs; the second one about the ability to walk 100 meters; and, finally, the third one about the ability to run 100 meters. Again, we look at the age groups 55-59 and 60-64.

It is apparent from the upper panel of Figure 6, showing the development for males and females together, that there is a steady improvement in all three measures and in both age groups over the observed period. The largest improvement is in the age group 60-64. In this group, the share of individuals that claim they are able to run 100 meters has increased from 50 percent in 1968 to 70 percent in 2010.

In the lower two panels of Figure 6 we show the development in the two age groups for males and females, separately. This division reveals that the development can to a larger extent be attributed to men. It can be seen that almost 80 percent of the men aged 60-64 claim that they are able to run 100 meters in 2010 compared to 62 percent for females. This gender gap was much smaller in 1968.

\footnotetext{
${ }^{1}$ The sample size of 6,000 individuals implies that there are on average about 100 observations in each birth cohort. Since we split the sample by gender and use five-year age intervals we get a sample size of around 250 observations in each cell we report.
} 


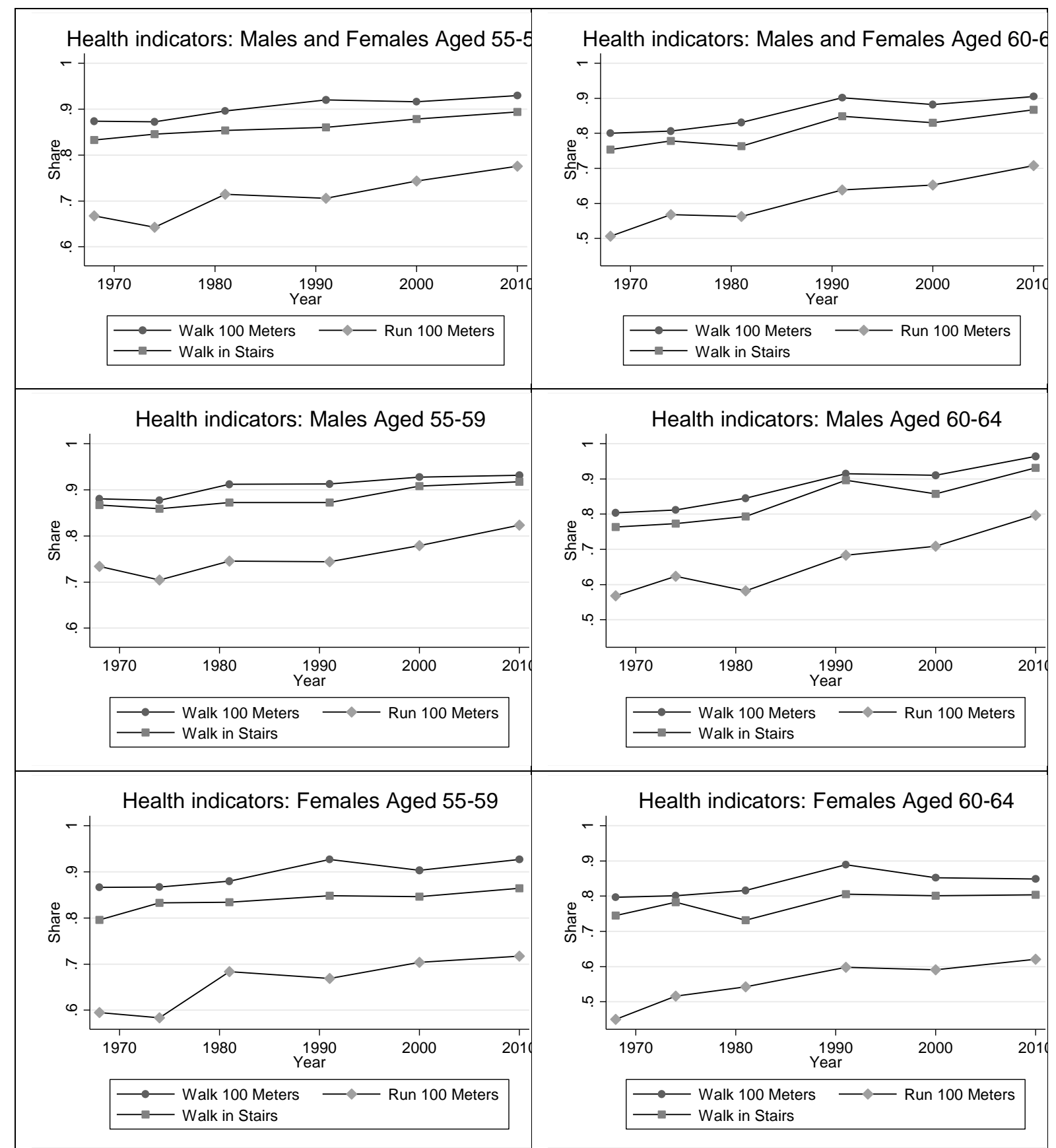

Figure 6. Share that are "Able to walk 100 meters", "Able to run 100 meters and "Able to walk in stairs". Age groups 55-59 and 60-64. Males and Females. Source: Own calculations from the 1968, 1974, 1981, 1991, 2000 and 2010 waves of the Swedish Level of Living Survey.

In the 1991, 2000 and 2010 waves of the LNU there is a summary measure of the individuals' health status from the answer to the question whether the respondent is in "Good", "Fair" or "Poor" health. Figure 7 shows the development of the share reporting fair or poor health over the three surveys. In the upper panel, the development is shown for males and females together divided in the age groups 55-59 and 60-64, respectively. The lower panels show the development for males and females separately. 
Figure 7 reveals that there is a substantial improvement in the health status measure over the almost 20-year period covered by the surveys. In the older age group, the share reporting fair or poor health decreases from almost 42 to about 32 percent. The lower panel shows that the improvement again primarily can be attributed to men. The largest change is in the older age group. Between 2000 and 2010 the share of those claiming to be in fair or poor health decreased from about 43 to below 25 percent - a decrease of about 40 percent.

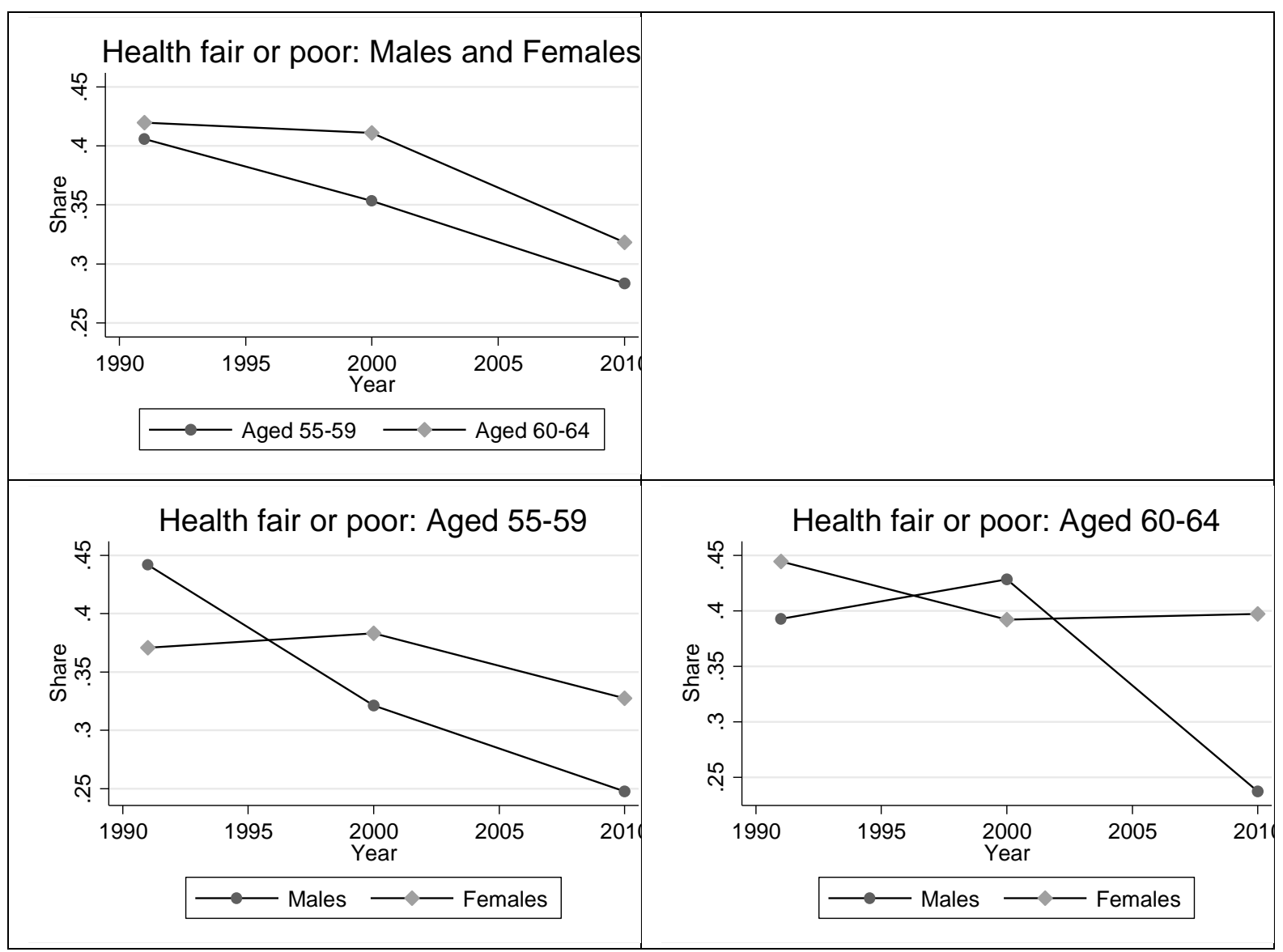

Figure 7. The development of the share that claim they are in fair or poor health. Age groups 55-59 and 60-64. Males and Females. Source: Own calculations from the 1991, 2000 and 2010 waves of the Swedish Level of Living Survey.

To sum up, we look at the development of three different types of measures for population health: mortality, self-assessed measures of physical ability and, finally, selfassessed summary health measures. Interestingly, all these measures give a similar picture of the development: there is a continuous improvement in health and it seems that there has been a somewhat accelerated improvement for older men in recent years. Improved health thus seems to be a prominent factor in explaining the rise in labor force participation among the elderly. In fact, in a previous study (Johansson et al. 2016), we find that the recent increase in 
labor force participation is smaller than the health improvement for older workers, if we assume that workers in a particular health status could work as much as workers with the same health status worked in the past.

\subsection{Changes in Educational Attainment}

It is well known from previous studies that more educated individuals retire later (see, e.g., Venti and Wise, 2015). Our Swedish data shows that the difference in the employment rate between low educated (compulsory schooling or vocational training as the highest level) and high educated (secondary schooling or higher) is 11.8 percentage points in the age group 5559 (72.3 versus 84.1 percent). The corresponding difference among 60-64 year olds is even larger: 14.3 percentage points (56.3 versus 70.6 percent).

A possible background to the increase in the labor force participation of older workers could therefore simply be that the cohort reaching older ages in recent years are more educated than previous ones and therefore retire later. Figure 8 shows the change in educational attainment for the age group 55-64 between 1985 and 2014. The left panel shows the share that has graduated from high school and the right panel shows the corresponding share of college graduates.

Figure 8 shows a great change in the educational attainment of the age group. The largest change is for women. During the period covered by Figure 8 educational qualifications of women surpassed those of males both measured as the share graduating from high school and from college. Between 1990 and 2005 the share of women aged 55-64 with a high school degree increased from below 30 percent to about 45 percent and the share graduating from college increased from around 10 percent to about 30. 


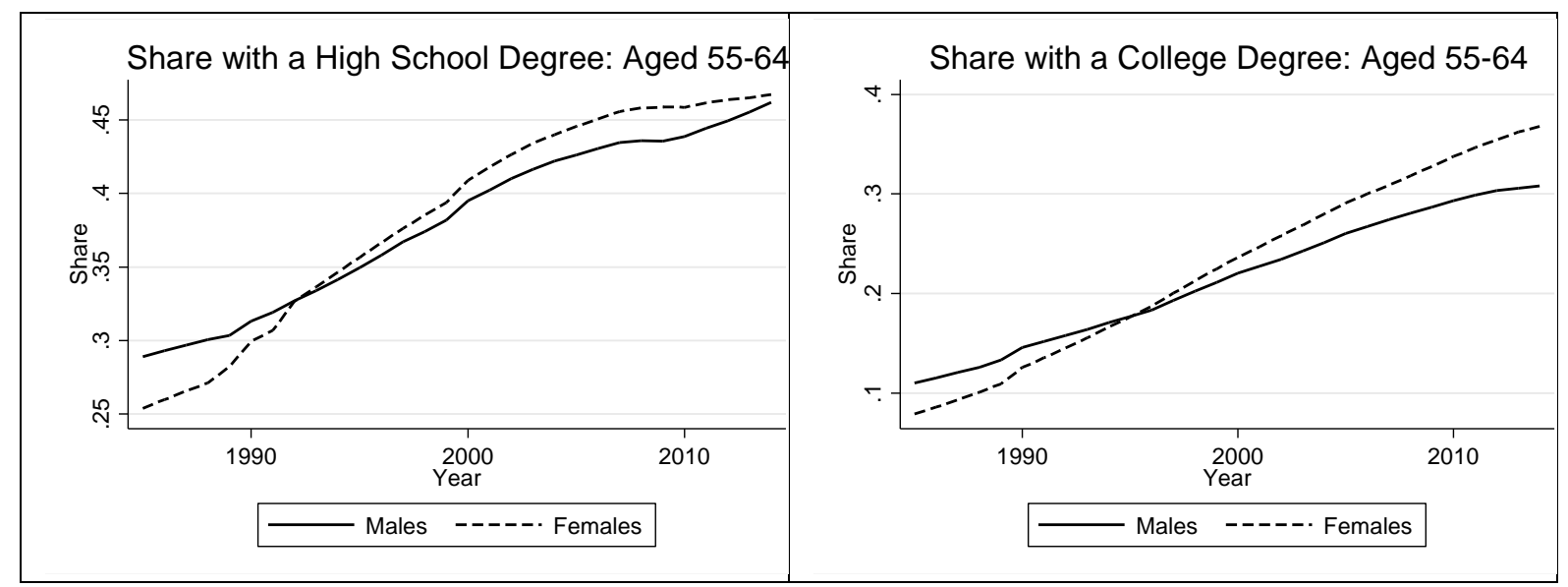

Figure 8. Left panel: Share of high school graduates in the age group 55-64 between 1985 and 2014. Males and Females. Right panel: Share of graduates from University/College in the age group 55-64 between 1985 and 2014. Males and females. Source: The Swedish Education Register.

In Figure 9 we have placed the graphs showing the change in educational attainment along with those showing the evolution of labor force participation in the age group 60 to 64 . Note that we have changed the age group for the education measures to the age group where most of the increased labor force participation took place. We have also changed the label of the $x$-axis to the year of birth of the mid-point of the age group under study, i.e., age 62. The left panel shows the results for males and the right one for females.
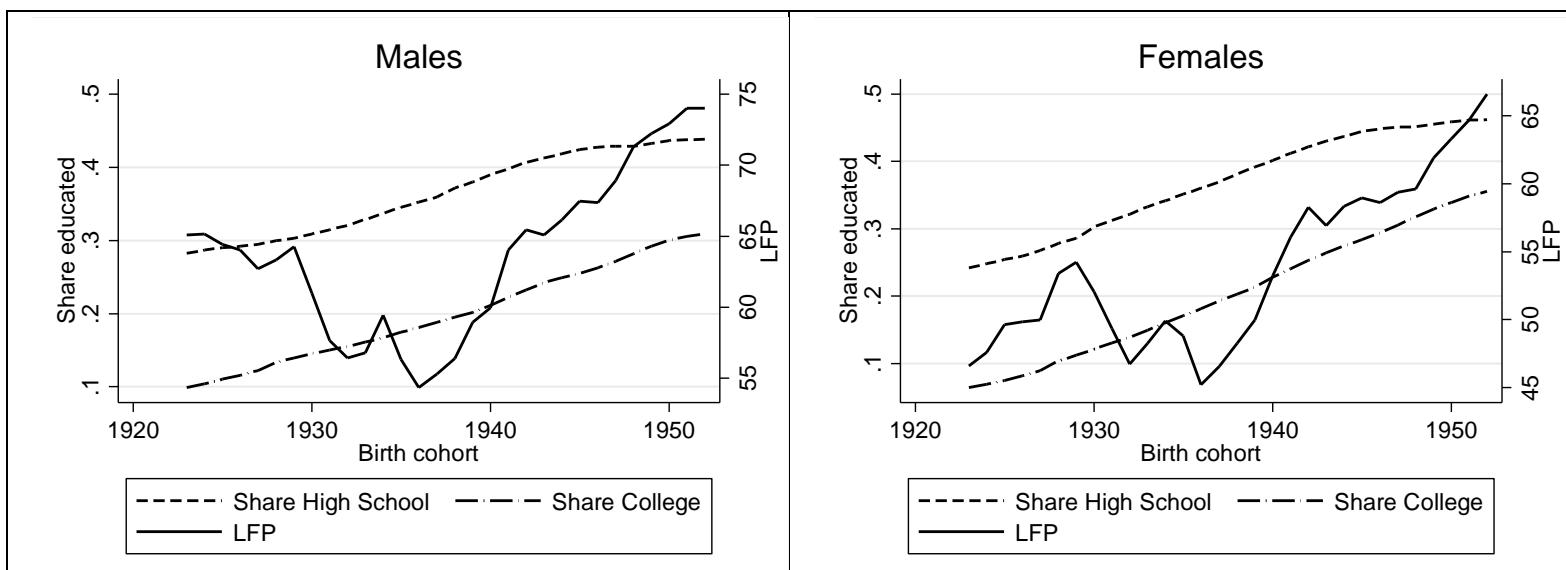

Figure 9. Development of labor force participation by cohort of birth and share graduating from High school and College/University, respectively in the age group 60-64. Source: Swedish Labour Force Survey and the Swedish Education Register.

The message in the graphs is somewhat mixed. On the one hand, one could argue that the educational attainment also increased across the birth cohorts born in the 1930s, when labor 
force participation in the age group actually decreased, and that labor force participation continued to increase also for the cohorts born in the 1950s, although the increase in educational attainment markedly slowed down. On the other hand, the graphs show that when the educational attainment grew the most, in particular for higher education, for the cohorts born in the 1940s, the labor force participation started to increase.

\subsection{Less Demanding Jobs}

It is well known that the jobs in post-industrial societies have become less physically demanding. This change could of course have contributed to the higher labor force participation rates in recent years. Let us therefore look into how the changes in the work environment match the changes in the labor force participation rates.

As for the measure of population health, there are different ways of measuring changes in the work environment. Figure 10 shows the number of deaths in work accidents between 1970 and 2014. The advantage of this measure is its high reliability, since all work accidents in Sweden have to be reported to the Swedish Work Environment Authority (Arbetsmiljöverket). ${ }^{2}$ The validity of the measure could, on the other hand, be questioned, since fatal work accidents are quite rare events and only reflect a very limited aspect of the work environment.

Figure 10 reveals a very steady trend towards fewer deaths for males in work accidents between 1970 and 2000. After that, the annual number of deaths in work accidents seems to have stabilized on a level of about 50 deaths. For females, the number of deaths in work accidents has been very low throughout the entire period, except for the spike in 1994 that can be attributed to the "MS Estonia" ship disaster. ${ }^{3}$

\footnotetext{
${ }^{2}$ Before 2001 called the National Board of Work Security (Arbetarskyddsstyrelsen).

${ }^{3}$ A cruise ferry that sank in the Baltic sea in September 1994. One of the worst maritime disasters in the $20^{\text {th }}$ century. 852 lives were lost. Among them a large group of Swedish municipality employees. Since the trip was work related, the casualties were classified as work accidents.
} 


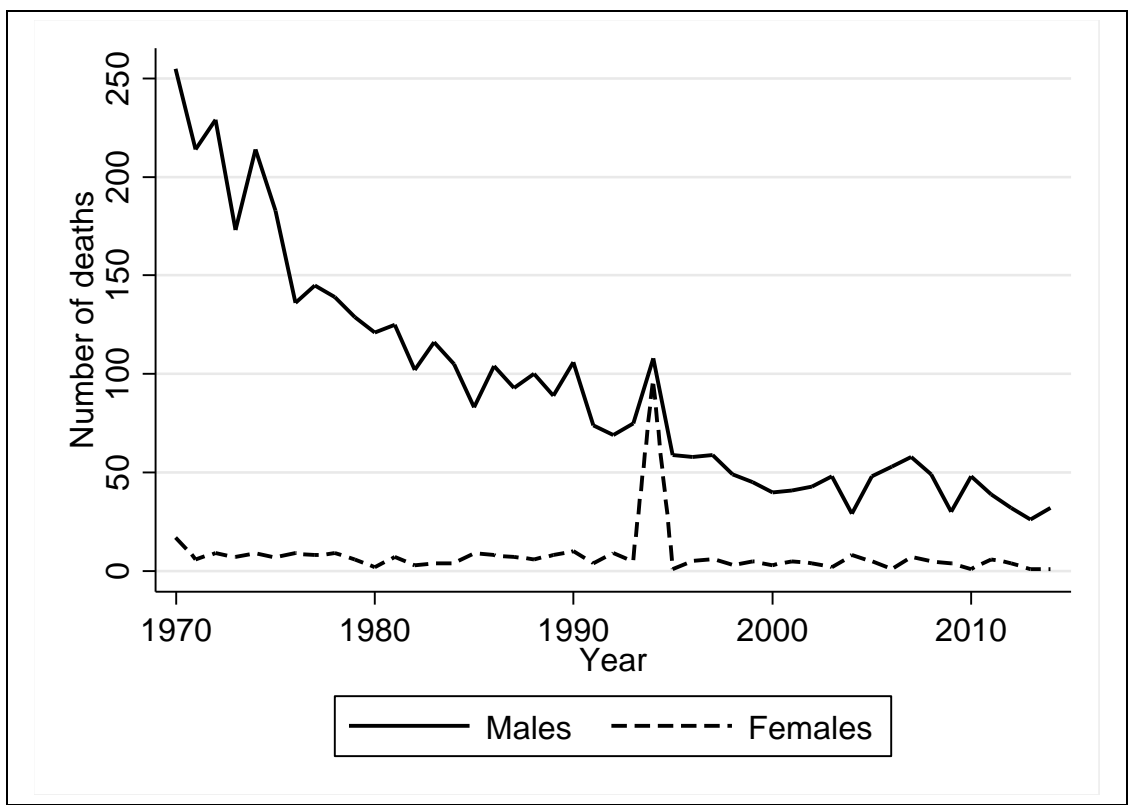

Figure 10. Number of deaths in work accidents between 1970 and 2014. Males and Females. Source: The Swedish Work Environment Authority.

Comparing the changes in the number of deaths in work accidents with the trends in labor force participation rates in Figure 1, it can be seen that the developments do not support the idea that changes in the work environment is a driving force behind the increase in employment among the elderly. During the great decrease in labor force participation among older men between 1970 and 2000, there was a large decrease in deaths in work accidents, and when there was no change in the number of deaths in work accidents after the year 2000, there was a marked increase in the labor force participation rates.

Figure 11 shows the evolution of three different measures of how the physical demands at work places have changed for the age groups 55-59 and 60-64, respectively. The data source is the six different waves - obtained in 1968, 1974, 1981, 1991, 2000 and 2010 - of the Swedish Level of Living Survey. The three measures are self-reported assessments of to what extent the work includes heavy lifts, if the respondent considers his or her work to be physically demanding and, finally, if the job requires "daily sweating” to be performed. The left panels show the results for the 55-59 age group and the right ones the results for the age group 6064. The upper panels show the results for both genders and the two bottom ones for the males and females, respectively. 


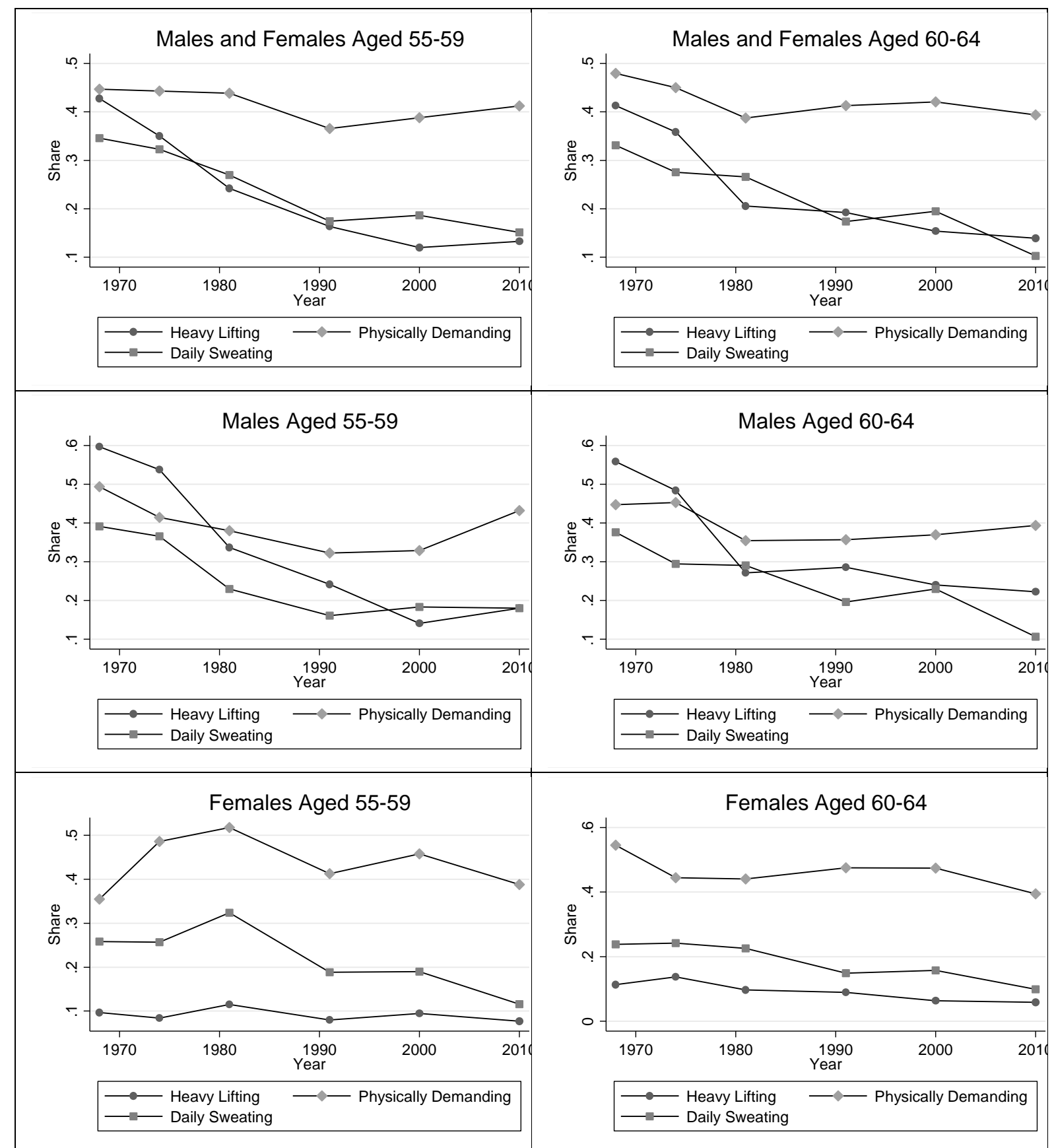

Figure 11. Development of three self-assessed measures of the physical work environment in the age groups 55-59 and 60-64. "Work including heavy lifting"; "Work considered to be physically demanding”; "Work requires daily sweating”. Males and Females. Source: Own calculations from the 1968, 1974, 1981, 1991, 2000 and 2010 waves of the Swedish Level of Living Survey.

The results show that there is a substantial reduction in the physical demands of the jobs in both age groups during the period covered by the surveys if we use the measure "Heavy lifting" and "Daily sweating". Looking at the graphs with the two gender groups combined, it can be seen that both these measures decrease from around 40 percent in both age groups in 
1968 to slightly above 10 percent in 2010. The graphs for the separate gender groups reveal that this development is primarily driven by the men. The third measure, to what extent the respondent considers his or her job to be physically demanding, changes very modestly over the period.

The results shown in Figure 11 do not support the hypothesis that lower physical demands at the labor market is the driving force behind the increase in labor force participation among the elderly. The results show that the largest decrease in the physical demands happened between 1968 and 1991 and can be attributed to the male workers. As we showed in Figure 1, the labor force participation rates decreased radically during these years. When the labor force participation for men increased, between 2000 and 2010, there appears to be little change in the physical requirements at the workplaces.

In addition to physical demands from work tasks, the psychological or social factors in the work environment may be important determinants for how long a person decides to stay in the labor force. Figure 12 shows the development of six different indicators for the psychosocial work environment on Swedish work places between 1986 and 2012 in the age group 5564. The left panels show the development for men and the right ones the corresponding developments for women. The upper panels show the share of workers who find their jobs "Stressful and monotonous"; who have chances "To learn new things" at work; and who find their jobs "Psychologically demanding”.

The lower panels show three different aspects of to what extent the workers feel that they are in command of their own work situation. First, whether or not they can "Plan their own work"; second, if they can "Decide their work pace”; third, if they can "Influence their work schedule".

Taken together, the graphs show very little change in all indicators except two. A larger share of the workers feel that they are able to learn new things at their work place and a lower share feel that they have no influence over their work schedule. The change of the first indicator is much larger for females: from 40 percent in 1986 to almost 75 percent in 2012. The corresponding change for males is from 60 to 75 . The change in work schedule flexibility is also larger for females, although the difference is much smaller. 


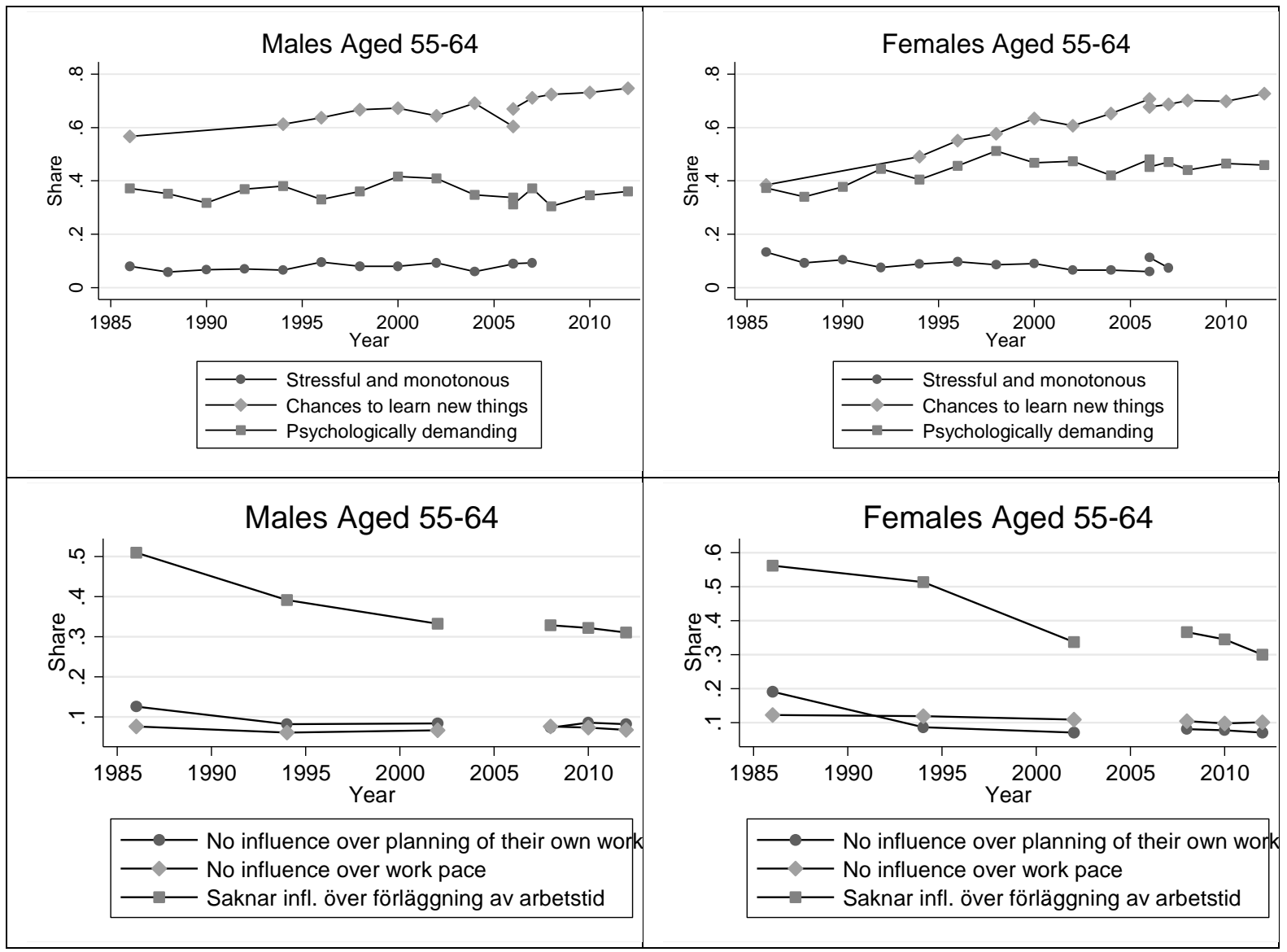

Figure 12. The development of psychological and social work environmental indicators 19862012. Males and Females. Source: Statistic Sweden ULF surveys 1986-2012.

\subsection{Joint Decision-Making}

As we documented in Section 2, an important change in the composition of the Swedish labor market since the 1960s is the feminization of the labor force. This change has implied a major shift in the finances and labor supply incentives of most Swedish families, including the incentives to exit from the labor force. The wives' participation decision may have two, counteracting, effects on the husbands' decision to remain in work. First, since the household's disposable income will increase as a result of the wife's income from labor it will create an income effect towards exiting the labor force for the husband. Second, since leisure time after retirement may be enjoyed to a larger extent if the husband could spend the time together with his wife, the wife's participation may decrease the husband's propensity to retire.

Several empirical studies have found evidence that the wife's retirement status significantly affects the husband's decision to leave the labor force (see e.g. Gustman and Steinmeier, 2000). Schirle (2008) finds that the increase in the male labor force participation rates since the mid-1990s in the US, Canada as well as the UK can to a substantial degree be 
attributed to increased female participation in the work force. To investigate to what extent this could also be the case in Sweden, we plot the labor force participation rates for females aged 35-44 lagged 20 years back in time along with the labor force participation rates for males in the age group 60-64. The reason for using lagged labor force participation rates for the cohort of women married to the men under study, rather than the current rates, is to avoid the obvious endogeneity problem when correlating the series.

The result from this exercise is shown in Figure 13. The figure shows that there is a joint positive trend in both series after the labor force participation rates among 60-64 year old men started to increase in the year 2000. However, it also shows that there is an even stronger increase in female labor force participation corresponding to the long downturn in participation of older men between 1980 and 2000. We thus have to conclude that husbands' responses to increased female labor force participation does not seem to be a dominating factor behind the recent increase in labor force participation of older men.

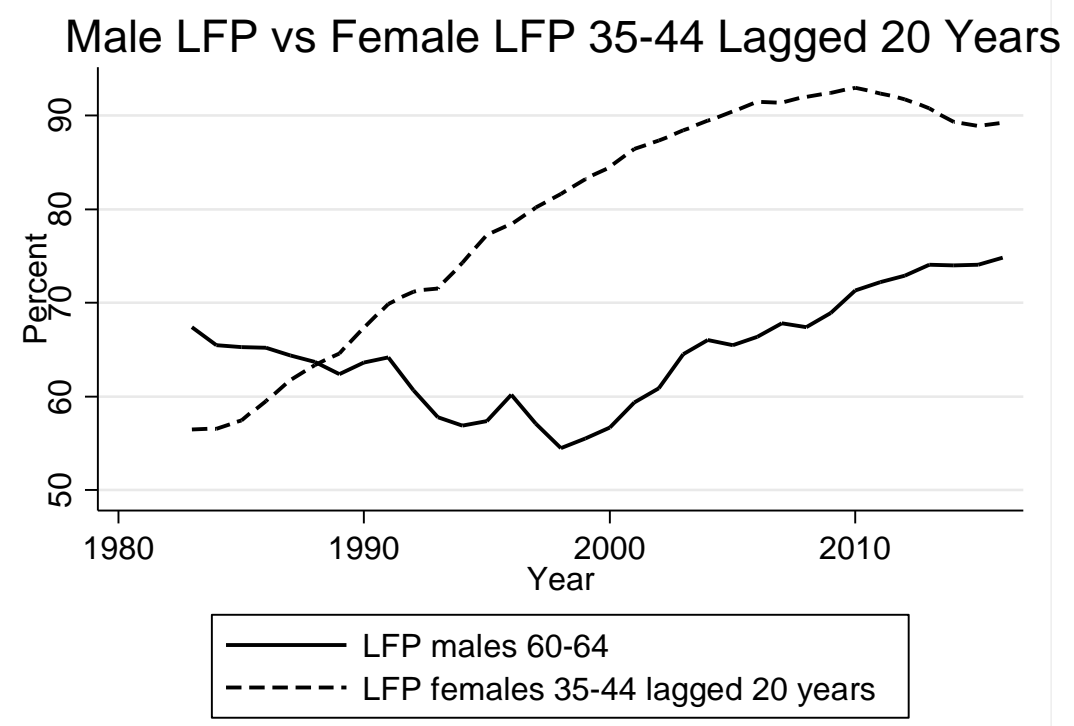

Figure 13. Labor force participation rates of Swedish men aged 60-64 along with labor force participation rates of females aged 35-44 lagged by 20 years between 1980 and 2016. Source: Swedish Labour Force Survey.

There are at least two possible explanations to why the increasing trend in female labor force participation did not seem to explain the delayed retirement of men in Sweden, while, according to the result obtained in Schirle (2008), this is the case in the US, Canada and the UK. First, the great expansion of female labor force participation happened more than a decade earlier in Sweden than in the countries included in Schirle's study. We are thus comparing 
different periods. Second, there may be differences in preferences in Swedish households compared to the countries studied by Schirle.

Two empirical studies on Swedish data support the second explanation. Selin (2017) investigates the husband's retirement responses to a change in the wife's retirement incentives and finds no significant effects, despite strong direct effects on the wife's labor force participation. Laun (2017) neither finds any significant retirement responses to spouses' prolonged work lives following the introduction of age-targeted tax credits in Sweden.

\section{Recent Institutional Changes Affecting Labor Force Participation of Older Workers}

\subsection{Swedish Pension Reform}

A major pension reform was decided in the Swedish parliament in 1998. The primary aim of the reform was to make the pension system financially robust. Projections showed that the prereform, defined benefit (DB) system required increased payroll taxes to be financially viable in an environment of an aging population. An additional aim was to strengthen the relation between the contribution made to the system and the benefits received - i.e., the actuarial fairness of the system - which affects the economic incentives for labor supply.

There were three main elements of the reform:

1. As opposed to the old supplementary, income-related defined benefit (DB) national pension plan (ATP), the new pension scheme is a so-called notional defined contribution (NDC) plan. The payroll tax devoted to the public old-age pension system is fixed to 18.5 percent of the individuals' annual wage sum in the new system. ${ }^{4}$ Of these, 16 percent is devoted to a pay-as-you-go system based on so called notional accounts and the rest, i.e., 2.5 percent, is devoted to a fully funded scheme.

2. The sizes of the individual benefits from the new pay-as-you-go scheme are proportional to the contributions made throughout the insured individual's life cycle. In the pre-reform scheme they are proportional to the earnings received during the individual's best 15 years at the labor market and with reductions if he or she contributed less than 30 years to the scheme. There was also an actuarial reduction of 0.5 percent for each month the pension was claimed before the $65^{\text {th }}$ birthday and a 0.7

\footnotetext{
${ }^{4}$ Due to a 7 percent tax deduction, the effective rate is actually $18.5 *(1-0.07)=17.21$ percent.
} 
percent increase for each month the pension was delayed after that age. There is no earnings test in any of the two pension systems.

3. A fully funded pension program was introduced. For this part, the insured individual is able to choose between a large number of private fund managers, or remain in the default fund, managed by the public authorities.

The new pension system was implemented gradually by year of birth. The first cohort to be covered by the post-reform system was those born in 1938 . They are by 20 percent in the post-reform system and by 80 percent in the pre-reform one. For every subsequent birth cohort the share of coverage from the new system is increased by 5 percentage points until those born in 1954, which are covered to 100 percent by the post-reform system.

Figure 14 shows the share to which each birth cohort is assigned to the new pension system along with graphs for labor force participation rates in the age group 60-64. The birth cohort corresponding to a particular year of labor force participation is calculated at the midpoint of the age group at age 62. It can be seen that there indeed is a striking resemblance between the implementation of the new public pension system across cohorts and the labor force participation rate in the age group under study. The increase in labor force participation starts with the cohorts born in the early 1940s and continues until those born in the mid-1950s. This applies for both men and women.

Our next step in investigating the credibility of the hypothesis that the pension reform contributed to the pattern of delayed retirement is to take a closer look at how incentives to remain in the labor force changed as a result of the reform and how that may have affected the retirement behavior for the period. Laun and Wallenius (2015) posed a related research question. They use a dynamic programing model calibrated on aggregate data for retirement behavior on the Swedish labor market and predict how the post-reform pension system would change retirement behavior when fully implemented. Their results suggest a very strong effect of the pension reform on retirement behavior: the retirement is predicted to be delayed by on average 2.5 years in the work force. 


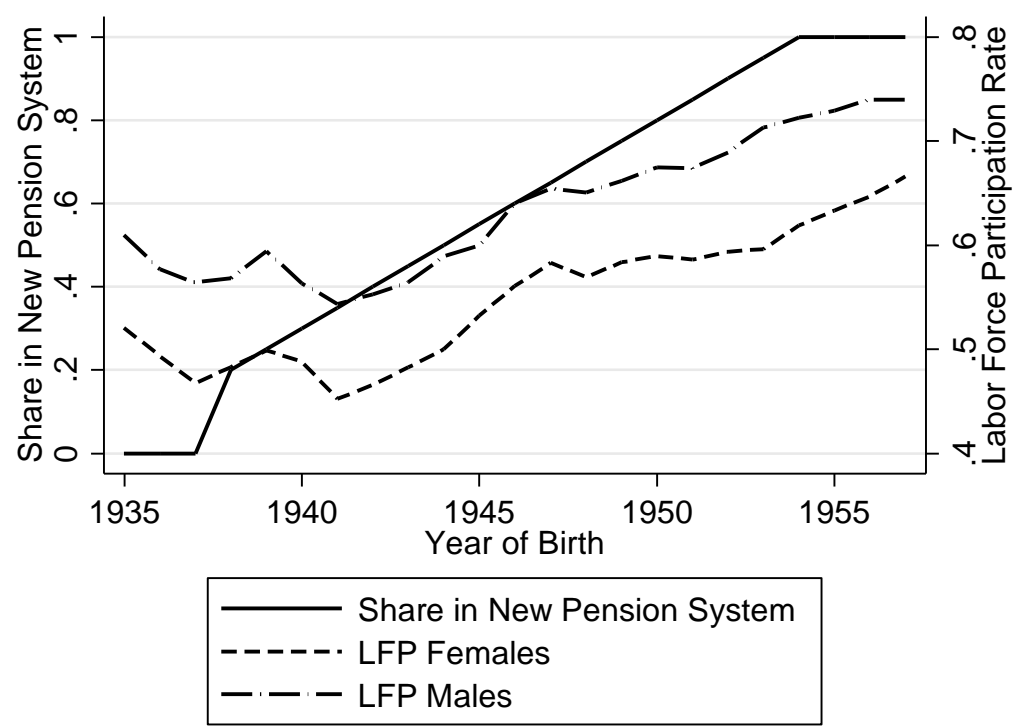

Figure 14. The implementation of the new Swedish old-age pension scheme and labor force participation rates in the age group 60-64 by cohort of birth. Males and females. Source: Swedish Labour Force Survey.

The retirement age, when the worker exits from the labor market, does not need to be the same as the age when he or she starts to claim pension benefits. A fundamental difference between the new and the old pension system is that the pension wealth in the new system is linked to when the worker stops to pay contributions to the system. In the old system the actuarial adjustment is linked to when the person starts to claim benefits. This means that there will be no actuarial adjustments if a worker retires at age 62, but starts to collect his or her pension benefits at age $65 .{ }^{5}$

This means that there are different economic incentives for the timing of labor market exit and for the timing to start to claim benefits. Laun and Wallenius look at the decision to exit from the labor market, stop contributing to the pension scheme, conditional on the date when the worker starts to claim benefits. This procedure assumes that the workers are not credit constrained in their retirement decision in the sense that they have to start to claim benefits at the same time as they retire. Under this assumption, the pension reform has a strong effect on the incentives to stay in the labor force.

\footnotetext{
${ }^{5}$ The actuarial adjustment in the new system is determined by an annuity divisor which is a function of life expectancy at the date when the person starts to claim benefits.
} 
To compare the economic incentives to stay at the labor market in the pre- and postreform pension systems, we first confine ourselves to the timing of claiming benefits. Figure 15 shows the results from a calculation of two incentive measures for a median income earner in the cohort born 1930. The first one, shown in the left panel, is the replacement level, calculated as the share of the pension income of median earnings the year before retirement. The second one, shown in the right panel, is the benefit accrual rate, calculated as the change in the social security wealth from delaying retirement one year. The dark lines with circles show the outcomes for the pre-reform system and the lighter lines with squares show the ones for the post-reform pension scheme.

The results show that the replacement level is somewhat lower in the new system. As a result of the different indexing in the two systems, this difference is to some extent dependent on the assumption about growth and inflation rates made in the simulations. We have assumed a growth rate of 1.6 percent and use real measures for the calculations. The results for the accrual rates show no great differences between the two systems. This confirms the conclusions of Palme and Svensson (1999) that the pre-reform system was not far from actuarially fair.

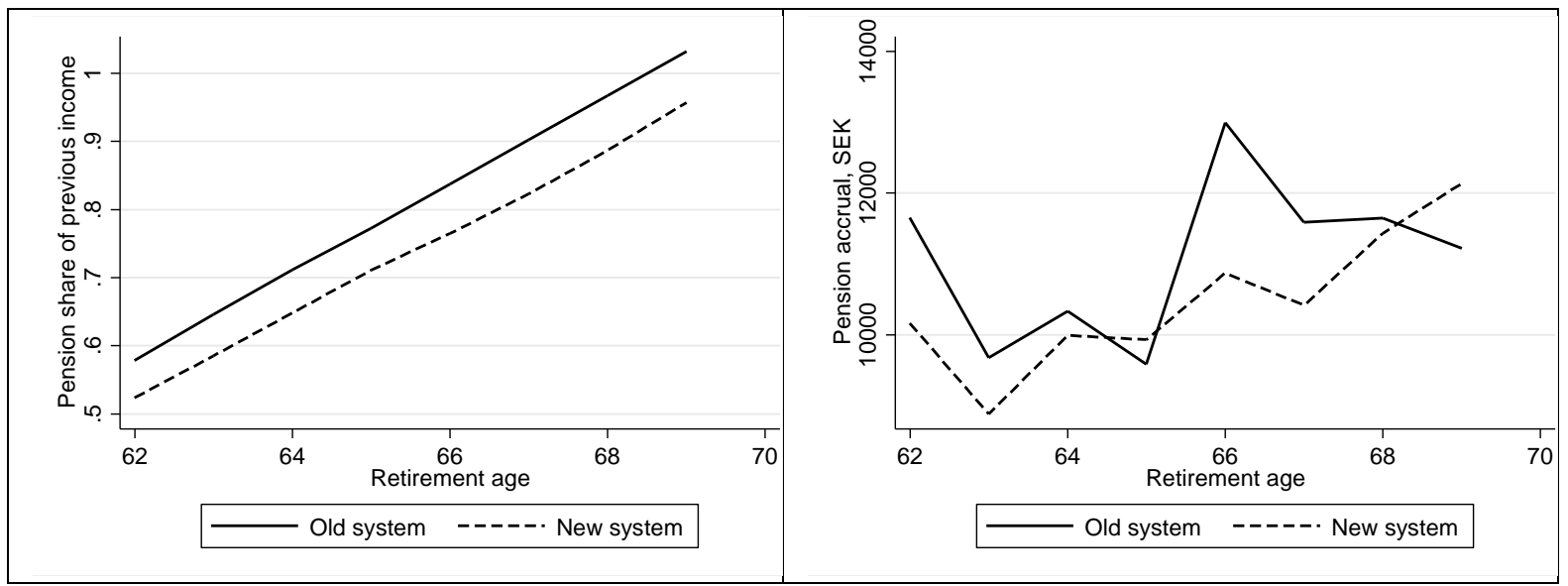

Figure 15. Left panel: replacement rate calculated as the ratio between the pension benefit and labor earning the year before retirement. Right panel: benefit accrual rates. Pre- and postreform pension systems, respectively. Source: Own calculations for a median income earner born in 1930.

Figure 16 shows the average age of pension withdrawal across the birth cohorts born between 1935 and 1944 for males and females, respectively. Three graphs are displayed in each panel: one corresponding to those who finance exit from the labor market by other income security programs than old-age pensions, namely through the disability insurance, the unemployment insurance or the sick pay insurance programs, one corresponding to those who 
receive old-age payment from public, occupational or private pension after they leave the labor force and, finally, the whole population, i.e., the two groups combined.

Figure 16 shows that very little has happened across the included cohorts, both among males and females. There is almost no change between the 1935 birth cohort and the one born in 1940. There is, however, a slight decrease of about 0.2 years in the average claiming age between those born in 1940 and 1944 in all groups and for both males and females. These small changes in claiming behavior are consistent with the small changes in incentives to delay claiming that we documented in Figure 15.

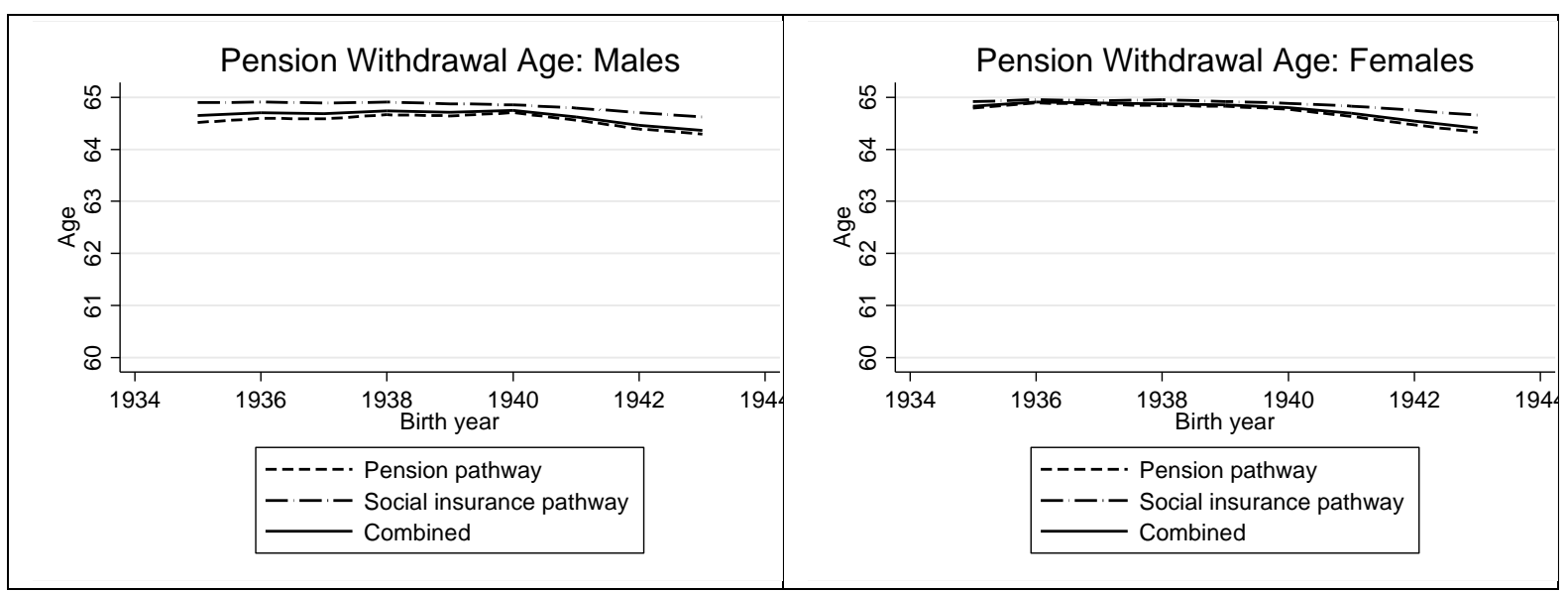

Figure 16. Average age of old-age pension withdrawal by pathway of exit from the labor market. Cohorts born 1935-1944. Males and females, respectively. Source: Own calculations from the LOUISE database.

We proceed by studying how retirement behavior has changed. The upper panel of Figure 17 shows how the average retirement age has changed across cohorts for males and females separately. The retirement age is defined as the age during the last observed year with earnings above one price base amount, followed by at least two years with earnings below one price base amount. There are three graphs in each panel: one showing the retirement age for the entire population and two for the old-age and the social insurance pathways separately. 


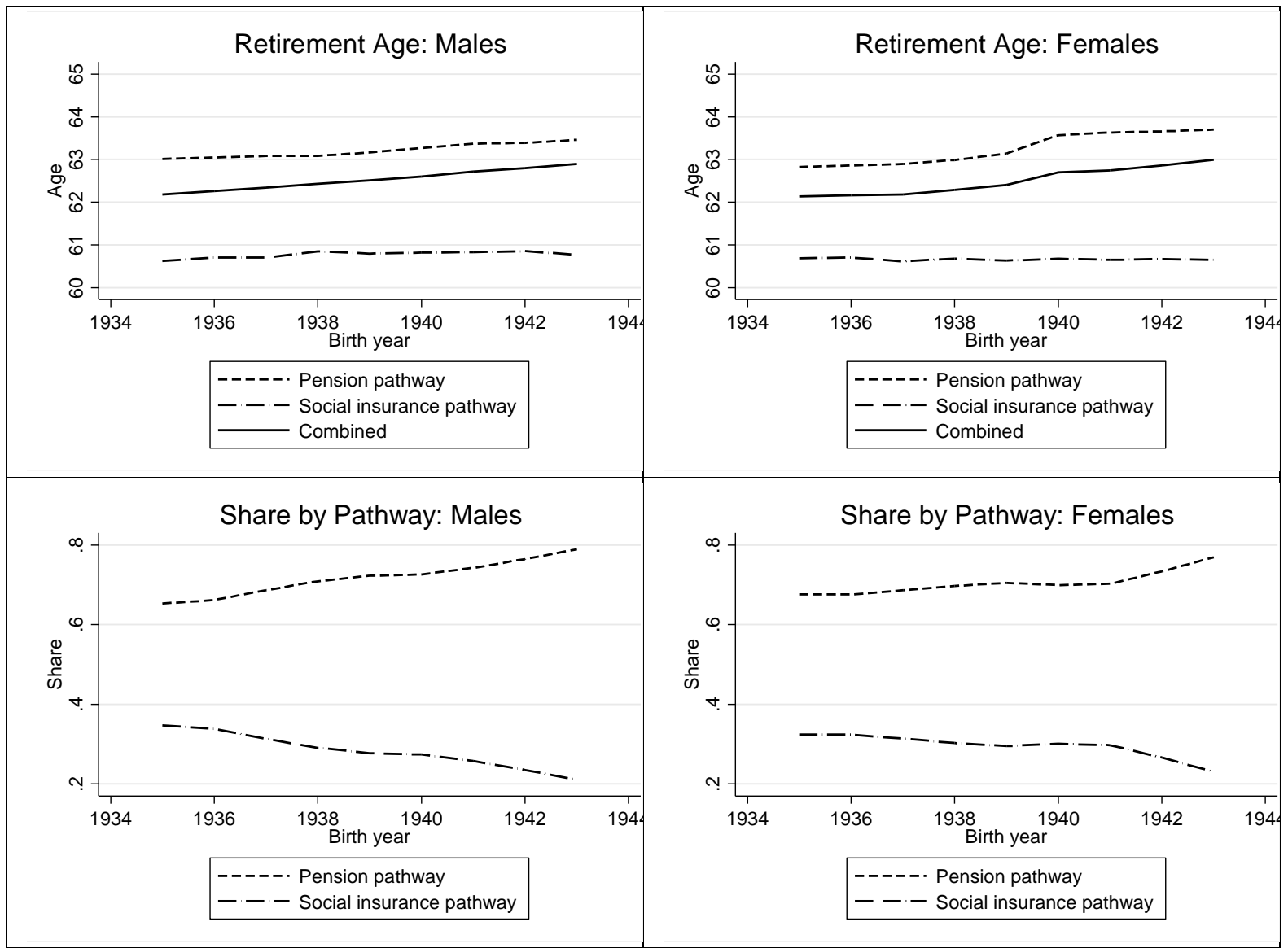

Figure 17. Upper panels: Average retirement age by year of birth. Lower panels: share exiting from the labor force by pathway of retirement and year of birth. Males and Females. Source: Own calculations from the LOUISE database.

The figure reveals an interesting pattern. First, for both men and women, the average retirement age has increased by almost a year from the first to the last cohort. For the social insurance path there has been no change. For the group using the old-age pension pathway, it is indeed a change toward delayed retirement, but the change is smaller than for the overall population. For men, the change in this group is about half of the change in the entire population.

This result suggests that there has been a compositional change to a smaller share using the social insurance pathway. This change is documented in the lower panel of Figure 17. As expected, the change is largest for the male sub-group, where there is a 15 percentage point decrease in the share leaving the labor force through the social insurance pathway: from 35 percent in the 1935 cohort to about 20 percent in the 1943 cohort. 
One way to assess to what extent the overall delayed retirement can be attributed to a larger share using the old-age pension pathway out of the labor force, or to what extent it can be attributed to the delayed retirement for those using this pathway, is to calculate the average retirement age by using the probabilities of the two pathways for the 1935 birth cohort and the average retirement ages for the 1943 cohort. This exercise tells us that about 55 percent of the overall change in the average retirement age for males over the period can be attributed to the change in the relative importance of the two pathways. The corresponding number for the female population is 33 percent, i.e., about one third.

The delayed retirement across cohorts for those who use the old-age pension pathway to leave the labor force is consistent with that the stronger incentives to stay in the labor force in the new pension scheme actually affected behavior. However, it is important to stress that there is also a compositional change across cohorts towards a larger share of individuals in the pension pathway with an inferior health, who with a more lenient screening in the older cohorts would have been eligible for disability insurance. This compositional change is counteracted by a general improvement in population health.

A necessary condition for the post-reform system to generate very different incentives for retirement is that the workers have access to a non-actuarially fair program to cover the time gap between he or she retires and starts to claim benefits. Johansson, Laun and Palme (2017) suggest that this was actually the case for some groups at the labor market, in particular white-collar workers in the private sector. In addition to that, there could also be individual agreements between the employer and the worker on severance payments, which also affect the incentives to retire.

A requirement for this to be empirically relevant is that there was on average a larger discrepancy between the date the individuals start to claim their pension benefit and when they actually retire in the older cohorts, with a stronger attachment to the pre-reform public pension system. Figure 18 examines if this is the case. The graphs show this gap for the three groups considered in Figures 16 and 17. The results show that the difference has indeed decreased for the group that exit through the old-age pension pathway. The change is largest for females, which concurs with the result that the largest change in retirement behavior was among females. 


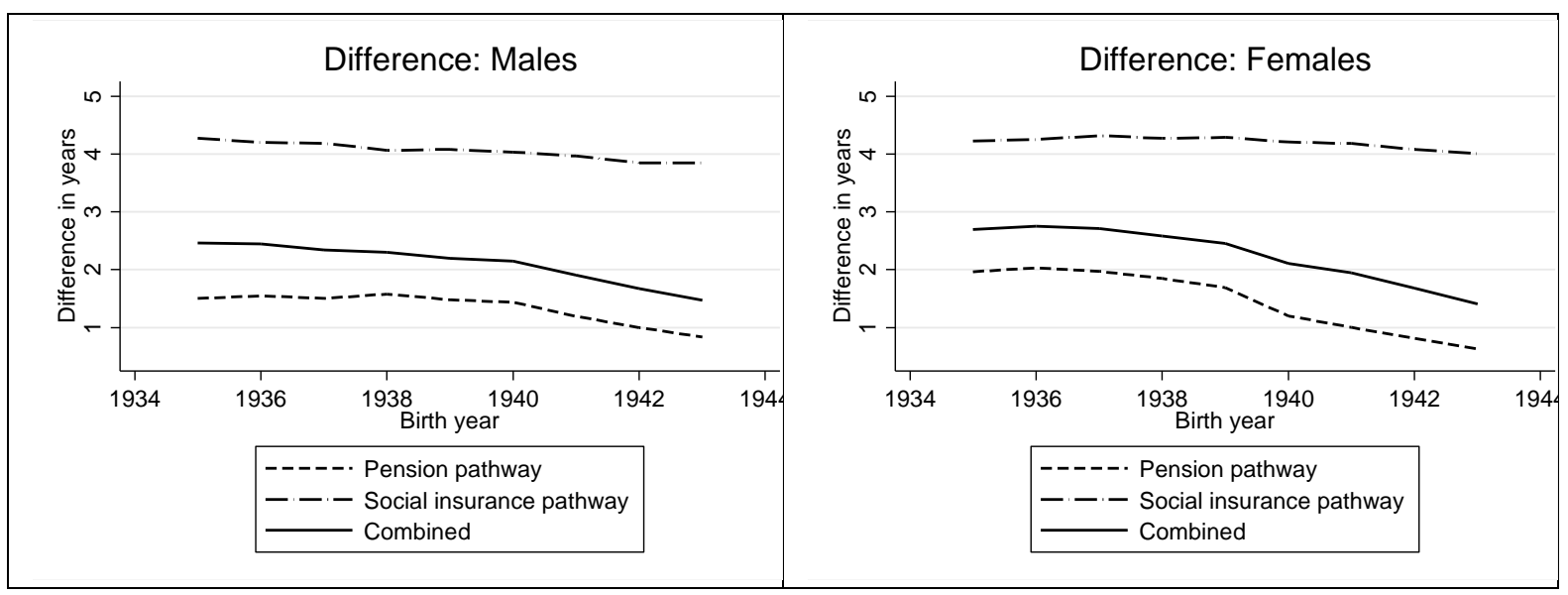

Figure 18. Difference between average age of exit from the labor market and average age of claiming of old-age pension benefits. Cohorts born 1935-1943. Males and Females. Source: Own calculations from the LOUISE database.

\subsection{Tax Reform in $\mathbf{2 0 0 7}$}

An earned income tax credit reform was introduced in Sweden in 2007 by the newly elected center-right government. The purpose was to encourage an increased labor supply, in particular among low income earners. Unlike in most other countries, the Swedish earned income tax credit was not phased out at higher earnings. Importantly, the size of the tax credit was larger for workers who were above age 65 at the beginning of the tax year. The earned income tax credit applies to earnings, but not to income from public pension or public transfers. The tax credit is a function of earned income, the basic deduction and the municipality income tax rate. An additional element of the 2007 reform was that the payroll tax rate was reduced from 26.37 percent to 10.21 percent for workers above age 65 at the beginning of the tax year. The purpose was to stimulate the demand for older workers.

Figure 19 shows how the net-of-participation-tax rate for workers below and above age 65 has changed during 1996-2010 for a median income earner. The figure takes the municipal and state income tax, the basic deduction, the earned income tax credit and the payroll tax rate into account. The net-of-participation-tax rate shows the net earnings as a fraction of the total wage cost to the employer. The reforms in 2007 substantially increased the net-ofparticipation-tax rate of workers above age 65. The introduction of the earned income tax credit also slightly increased the net gain from working for workers below age 65, although not to the same extent. 


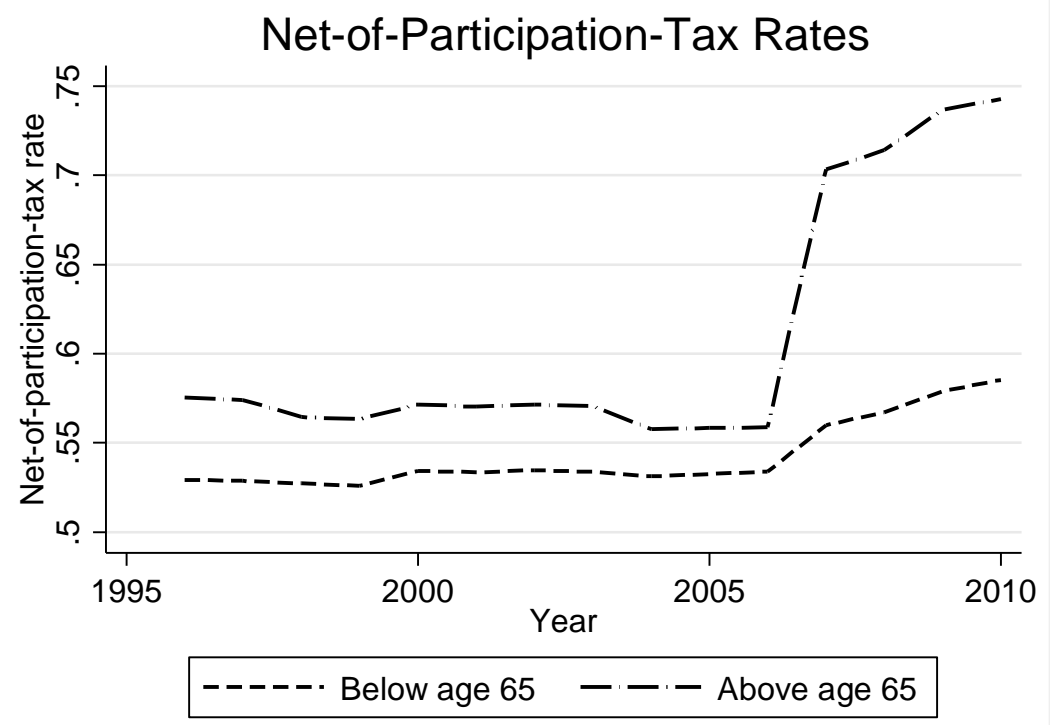

Figure 19. Changes in net-of-participation-tax rate for a median income earner below and above age 65. 1996-2010. Source: Own calculations from the LOUISE database.

Laun (2017) analyzes the combined effects of the earned income tax credit and the payroll tax reduction for workers above age 65, and finds that the tax credits increased employment at the extensive margin among workers just above age 65. The participation elasticity was estimated to 0.22 , amounting to an increase in labor force participation of about 5 percent. Even if the effect of the age-targeted tax credits is significant, it is relatively small. However, the tax credits have probably contributed to ease up the strong norms about retiring on the $65^{\text {th }}$ birthday.

For workers below age 65, there is no evidence of whether the smaller change in the tax burden due to the introduction of the EITC in 2007 has impacted the retirement decision in these ages. For these age groups, the increase in labor force participation began long before the age-targeted tax credits came into place. The tax credits can probably primarily explain the increased labor force participation for individuals above age 65.

\subsection{Changes in Mandatory Retirement Ages}

Almost all of the labor market in Sweden is covered by central agreements between trade unions and employers' confederations. In most cases these agreements include retirement ages for the workers. Before 2001, most agreements had a stipulated retirement at the $65^{\text {th }}$ birthday. 
This was also supported in the labor market legislation. Workers older than age 65 were not covered by employment security legislation and exempted from seniority rules. They were not covered by unemployment insurance (UI), disability insurance (DI) or the compulsory sick pay insurance. Central and local government employees automatically lost their jobs at age 65 . Exceptions from this rule were permitted for one year.

In September 2001, the government started to implement a legislation that enabled all employees to remain until age 67. This means that they were now covered by the employment security legislation. The rule that all central and local government employees automatically lost their jobs at age 65 was now postponed to age 67. However, the rules for the income security programs remained at age 65 also after the reform. Depending on ongoing collective agreements in some sectors of the labor market, the reform was not fully implemented until 2003.

There seem to have been very small effects of the reform on labor force participation rates above age 65. Going back to Figures 1 and 3, there are no visible changes in labor force participation rates or employment in the years following the reform. This reform could, however, have affected the long-term trend towards increased labor force participation of 6569 year olds.

\subsection{Stricter Rules for DI Eligibility}

The disability insurance (DI) program has undergone several changes in the recent decades. Before 2003 it was a part of the old-age pension system. It consisted of a basic pension and a supplementary pension. The benefits were related to the insured worker's income from labor and were determined using the same algorithm as for the old-age pension benefits. Since 2003, as a part of the reform of the Swedish pension system, DI is independent of the old-age pension program and is now a part of the social insurance system. The benefits are calculated as 64 percent of the "assumed income" below the social security ceiling. The "assumed income" is the average of the five to eight best years of annual income from labor before the worker became eligible to DI.

In the early 1970s the eligibility rules for DI were changed from admitting eligibility due to health problems to also admit eligibility due to labor market reasons, first in combination with health problems and subsequently for pure labor market reasons for workers older than age 60 who have been long term unemployed. In 1991 eligibility to DI for pure labor market 
reason were abolished and in 1997 it was abolished for labor market reasons combined with health deficiencies.

The reform in 2003 also included changes in eligibility rules for DI. The most important change was that the DI benefit was no longer permanent; eligibility would be reconsidered every $5^{\text {th }}$ year. In 2008 the government implemented a new reform of the DI system. The most important element of the new eligibility rules was that the person applying for DI had to show that his or her ability to work was permanently lost. This change was considered to be a very large increase in the stringency of the eligibility rules.

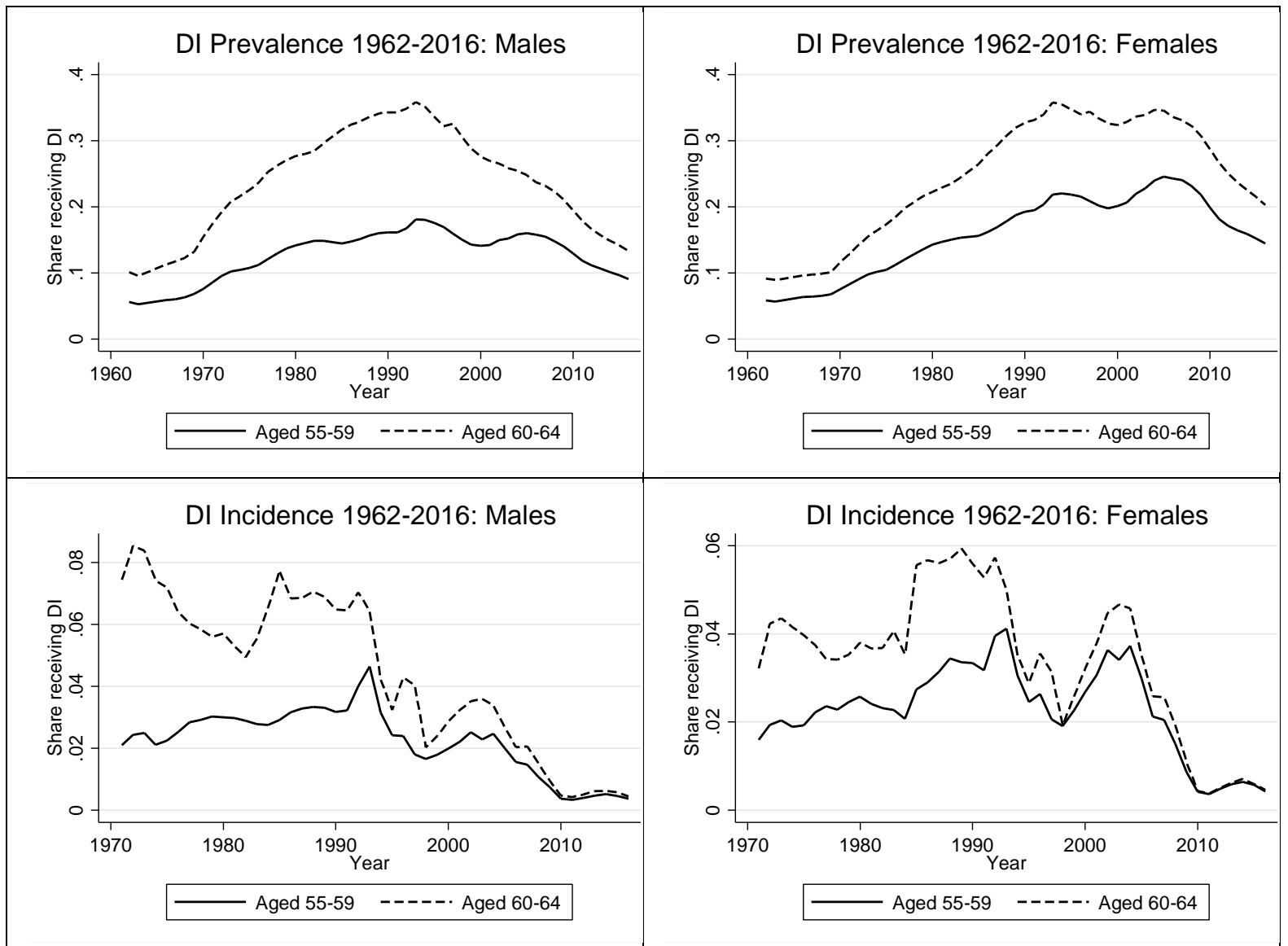

Figure 20. Upper panels: Share of the population receiving DI in different age groups, 19622016. Lower panels: Lower panels: Share of DI entry in different age groups, 1971-2016. Males and Females. Source: Swedish Social Insurance Agency.

Figure 20 shows the development of DI participation between 1962 and 2016 and the development of DI entry between 1971 and 2016 for males and females, respectively. The most striking result in Figure 20 is the sharp drop in DI entry from the late 1980s to today. The analysis in Jönsson et al. (2012) indicates that changed eligibility criteria during the 1980s and 1990s clearly affected program caseloads, and may also have had an impact on labor force 
participation. However, for our purposes the most interesting change is the decline in DI entry since 2005. It is apparent that the background to the decline is the more stringent eligibility rules following the reforms of the DI system in 2003 and 2008, and the changed implementation of the rules at the Swedish Social Insurance Agency during this period.

\section{Conclusions}

In this paper we have investigated the background to the increase in male labor force participation rates since the mid-1990s. In the first part, we looked at changes in the composition of the population related to the likelihood of being employed. In the second part we investigated to what extent institutional changes may have had an effect on the delayed exit from the labor force.

In the first part, we looked specifically at four changes in the Swedish population: (1) The improvement of the population health; (2) The increase in the educational attainment of the labor force; (3) The improved physical work environment; (4) The increase in female labor force participation rates. For the first two changes, we found that it is likely that they have contributed to the increase in labor force participation of older men. Although there has been a continuous change in mortality rates for men in the age groups 55-59 and 60-64, it seems like the changes have been stronger in recent years. This picture is confirmed also by the selfassessed measure that we reported. Also the changes in educational attainment seem to have contributed. Again, there is a trend towards more education across the birth cohorts, but the increase seems to have been stronger, in particular for higher education, in the cohorts born in the early 1940s, who were in their early 60s in the beginning of the 2000s.

For the second two changes, we found no support for that they would have been important for the increased employment rates for older men. The largest improvement in work environment seems to have happened earlier, already in the 1980s, when the labor force participation rates of men were still decreasing. The same seems to be true for the increased female labor force participation rates and the joint retirement decisions hypothesis: the great increase in the relative labor force participation rates happened across the cohorts born in the 1930s, for which the labor force participation rates in the older age groups were decreasing.

In the second part of the paper, we studied the effects of four institutional changes that may have led to delayed exit from the labor market. The stricter rules for DI eligibility, and the 
implementation of these rules at the Social Insurance Agency, appears to have had a very strong impact on labor force participation. Also the income tax reductions due to the earned income tax credit and payroll tax reduction for older workers seem to have delayed labor force exit, while the 2001 reform of the mandatory retirement age seemed to have had a surprisingly small immediate effect on labor force participation in the age group 65-69.

For the most important policy change during the era under study, the great reform of Sweden's public old-age pension system, there are a number of circumstantial evidence for that it actually did affect retirement behavior through changes in labor supply incentives. First, the staggered implementation of the reform across cohorts coincides with increased labor force participation rates. Second, a large share, about 45 percent for men and around 67 percent for women, of the delayed exit from the labor market that we observe for the cohorts between those born in 1935 and 1943 can be attributed to the group that retire through the old-age pension pathway. Third, we observe a smaller average gap between when the workers retire and when they start to claim their benefits from the public old-age pension program, which is consistent with the presumption that the pension reform actually implied changes in labor supply incentives of the elderly.

The research methodology used in this study does not, however, allow us to identify the magnitude of the effects that worked through changes in the labor supply incentives separately from the changes in health status and educational attainment that we also document. This important issue is left for further research.

We have limited this overview to only look at the supply side of the background to the changes in labor force participation older workers. The demand side - involving the effects of technical change, employers’ perception of worker productivity and age discrimination in work groups - is potentially as important, but also, for now, left for further research. 


\section{References}

Gustman, A. L. and T. L. Steinmeier (2000) "Retirement in dual-career families: A structural model” Journal of Labor Economics, 18(3), 503-545.

Johansson, P., L. Laun and M. Palme (2015), "Pathways to Retirement and the Role of Financial Incentives in Sweden”, in David A. Wise (ed.), Social Security Programs and Retirement around the World: Disability Insurance Programs and Retirement, Chicago: University of Chicago Press.

Johansson, P., L. Laun and M. Palme (2017), "Health, Work Capacity and Retirement in Sweden”, in David A. Wise (ed.), Social Security Programs and Retirement around the World: The Capacity to Work at Older Ages, Chicago: University of Chicago Press.

Jönsson, L., M. Palme and I. Svensson (2012), “Disability Insurance, Population Health, and Employment in Sweden”, in David A. Wise (ed.), Social Security Programs and Retirement around the World: Historical Trends in Mortality and Health, Employment, and Disability Insurance Participation and Reforms, Chicago: University of Chicago Press.

Laun, L. (2017), "The effect of age-targeted tax credits on labor force participation of older workers”, Journal of Public Economics, 152, 102-118.

Laun, T. and J. Wallenius (2015) "A life cycle model of health and retirement: The case of Swedish pension reform” Journal of Public Economics, 127, 127-136.

Palme, M. and I. Svensson (1999) "Social Security, Occupational Pensions, and Retirement in Sweden” in Jonathan Gruber and David Wise (eds.) Social Security and Retirement around the World, Chicago University Press: Chicago.

Schirle, (2008): T. "Why Have the Labor Force Participation Rates of Older Men Increased since the Mid-1990s?” Journal of Labor Economics 26(4), 549-594.

Selin, H. (2017), "What happens to the husband's retirement decision when the wife's retirement incentives change?”, International Tax and Public Finance, 24(3), 432-458.

Venti, S. and D. A. Wise (2015) “The long reach of education: Early retirement” The Journal of the Economics of Ageing, 6, 133-148. 